REVISTA CHILENA DE LITERATURA

Noviembre 2020, Número 102, 289-310

\title{
MACBETH Y LA DESTRUCCIÓN DEL TIEMPO COMO MOTIVO LITERARIO
}

\author{
Raluca Ciortea \\ Investigadora independiente \\ Montevideo, Uruguay \\ dra.ralucaciortea@gmail.com \\ Martín Fleitas González \\ Universidad de la República \\ Montevideo, Uruguay \\ elkanteano@gmail.com
}

\section{RESUMEN / ABSTRACT}

El artículo se propone analizar los diferentes momentos que atraviesa el tiempo en Macbeth, para argumentar que su destrucción y enigmática restauración responden a la empresa que persigue Macbeth con el aceleramiento de los eventos pronosticados por las hermanas extrañas, y conforman de este modo uno de los motivos literarios más importantes de la obra. Para ello, el trabajo reconstruye, en primer lugar, los rasgos generales que hacen al tiempo un auténtico motivo literario dentro de la obra shakesperiana; luego identifica las evocaciones temporales que descansan en Duncan, Lady Macbeth y Macbeth mismo; y, finalmente, detalla el proceso por medio del cual Macbeth logra destruir o suspender el tiempo, permitiéndole a los autores analizar algunas de las inquietudes literarias e intelectuales que Shakespeare podría haber perseguido con ello.

Palabras ClaVE: Shakespeare, Macbeth, tiempo/orden, destrucción, motivo literario.

\section{MACBETH AND THE DESTRUCTION OF TIME/ORDER AS LITERARY MOTIF}

The article intends to describe and analyse the different moments that time goes through in Macbeth, to argue that its destruction and enigmatic restoration respond to the endeavour that Macbeth pursues with the acceleration of the events predicted by 'the weird sisters', and thus structures one of the most important literary motifs of the play. To do this, the paper reconstructs, first of all, the general features that make time an authentic literary motif within 
the Shakespearian play. Furthermore, it identifies the temporal evocations that are evident in Duncan, Lady Macbeth and Macbeth. Finally, it details the process by which Macbeth manages to destroy or suspend time. This allows the authors to analyse some of the literary and intellectual concerns that Shakespeare could have pursued.

KEYWORDS: Shakespeare, Macbeth, time/order, destruction, literary motif.

Recepción: 09/11/2019

Aprobación: 05/03/2020

\section{INTRODUCCIÓN}

No es nada novedoso afirmar que Macbeth gira en torno al malestar que genera el tiempo descoyuntado, aunque este último sea bastante diferente al que refiere Hamlet cuando exclama "The time is out of joint: $\mathrm{O}$ curs' $\mathrm{d}$ spite / That ever I was born to set it right!" (1.5.189-190) ${ }^{1}$. Esto se debe a que Hamlet nunca deja en claro cuál es el tiempo que debe corregir, así como tampoco explica las razones que le hacen creer que es él quien debe hacerlo ${ }^{2}$, lo que genera la sensación de que su tarea implica sumergirse en el tiempo para resolver su crisis; mientras el caso de Macbeth se caracteriza por repudiar al tiempo como tal, declarándole la guerra, y optando por volarlo desde sus más recónditos cimientos. Esta diferencia es muy importante. La mayoría de los indicios textuales sugieren que el príncipe danés, heredero de un antiquísimo linaje vikingo, no podía sacudirse así como así los deberes que el antiguo tiempo/orden le legaba, aunque el desafío de consumar tales obligaciones supusiese aprender a jugar en el tiempo/orden impuesto por Claudius, a saber, aquel lineal del cálculo, de la manipulación, y de las apariencias cortesanas. Macbeth, por su parte, rechaza la tarea de corregir el tiempo dislocado, y opta por asumir la tarea de superarlo, sea destruyéndolo al convertirlo en eternidad, o suspendiéndolo al compactar el pasado y el futuro en un amplio e insuperable presente. Esta lectura es, precisamente, la que se elaborará a lo largo del presente trabajo.

Dentro de este contexto, y a pesar de lo desafiante y esquivo que resulta al asunto del tiempo en Macbeth, nos proponemos describir y analizar los

$1 \quad$ Las citas de Hamlet son extraídas de la edición de Philip Edwards de 2003.

2 Edward H. Seymour observa que "Hamlet does not lament that the disjointed time is to be set right by him, but that he, (...) and whose duty it of necessity becomes, to set the time right, should have been born" (Seymour 164). 
diferentes momentos que aquel atraviesa hasta concluir en su destrucción y enigmática restauración, y conformar así un motivo literario central de la tragedia narrada. Para ello señalaremos los rasgos generales que hacen al tiempo un auténtico motivo literario dentro de Macbeth (1), reconstruiremos las evocaciones temporales que descansan en Duncan, Lady Macbeth y Macbeth (2) y, finalmente, detallaremos el proceso por medio del cual Macbeth logra destruir o suspender el tiempo, permitiéndonos analizar algunas de las consecuencias literarias e intelectuales que Shakespeare podría haber perseguido con ello (3).

\section{EL TIEMPO/ORDEN COMO MOTIVO LITERARIO EN MACBETH}

Si bien la obra parece estar total y explícitamente empeñada en narrar peripecias que se dan en medio de las vicisitudes que el tiempo desencadena en el mundo humano, y de las crisis que estos últimos producen en aquel a través de un accionar permanente, el tiempo de Macbeth se vuelve un problema en sí mismo desde el mismo momento en que notamos la equivocidad, sinuosidad y omnipresencia del término ${ }^{3}$. La principal causa de esta huidiza problemática estriba en que a lo largo de la obra el tiempo no deja de emigrar de un significado a otro. Pero la dificultad del asunto no ha hecho más que alentar las discusiones crítico literarias. En rasgos generales, parece no presentar mayores inconvenientes partir de la premisa de que el núcleo del conflicto temporal que envuelve a Macbeth se conforma alrededor de la ya entonces notoria decadencia que padece una era llena de significados valiosos para las sociedades británicas ${ }^{4}$. Dentro de este escenario se entiende que la

\footnotetext{
"Tiempo" (Time) es intensa y recurrentemente usado en todas las obras de Shakespeare, abrigando, en numerosas ocasiones, significados muy diversos. Para apreciar con precisión la equivocidad shakespeareana de "tiempo" consúltese Schmidt.

Muchos rasgos de esta "era" se encuentran atravesados, si no determinados, por el contexto histórico, social y cultural en el que se escribe y publica Macbeth. Hacia finales del siglo XVI y principios del XVII, había emergido en Inglaterra un debate algo público, algo social, acerca de la legitimidad de la tradicional norma de sucesión, incluidas sus tiranías y usurpaciones. Philip J. Ayers (461-474), por ejemplo, ha argumentado que las ficciones isabelinas que retratan "buenos vengadores" podrían haber sido muy bien recibidas por una audiencia que trataba de reaccionar desafiantemente a los sermones, enseñanzas y parábolas religiosos que no consentían la rebelión. Para el contexto histórico de este asunto véase el
} 
reacción humana no podría haber sido otra que la de querer apropiarse de la temporalidad e intentar sobreponerse a la confusa transición histórica a través de su congelamiento: "Away and mock the time with fairest show" (1.7.83-84).

Para apropiarse de la transición, Macbeth no duda en personificar el tiempo, desafiándolo e intentando aventajarle para finalmente hallarle vacío y sin sentido. Pero el esfuerzo de personificar el tiempo se resquebraja a lo largo de la obra; la temporalidad se le escurre una y otra vez entre sus dedos a través de lo incierto. A la inicial pregunta "When shall we three meet again?" (1.1.1) le suceden una serie de respuestas confusas y cada vez más distantes de lo humano, dando a luz un tiempo fantasmagórico que en modo alguno puede ser capturado, sino tan solo presentido a través de las sombras voraces que su manto deja entrever al cobijar todo lo que aparece, desparece y fluye en el mundo; un tiempo que solo puede sentirse "When the battle's lost and won.” (1.1.4). De ahí que no sea sencillo determinar con precisión cuál es el auténtico contenido de aquella temporalidad.

A esto se incorporan los diferentes elementos de la obra que con mayor claridad pueden convertir al tiempo/orden en un auténtico motivo literario. Desde la antigüedad hasta el Renacimiento, las sociedades noroccidentales asocian estrechamente al tiempo cronológico con un orden cósmico, natural y sagrado, que ampara y orienta, al mismo tiempo, las diferentes maneras de organizar lo social ${ }^{5}$. De ahí que el binomio tiempo/orden sea el elemento trastornado durante la tragedia, una vez que el orden humano aspira a independizarse del tiempo a través de su manipulación: (i) la observación de que Macbeth es por mucho la tragedia más breve de Shakespeare; (ii) la constatación de que la obra comienza abruptamente con la predicción de las "hermanas extrañas", incluyendo un feroz asesinato hacia el final de 2.1; (iii) y la intensidad del lamento que Macbeth dispara en aquel célebre soliloquio pronunciado tras el fallecimiento de su esposa (5.5.17-27). La ligazón que estas coordenadas traban entre el tiempo y el orden natural y social percibido en la época impulsan, de buenas a primeras, la idea de que Shakespeare ha intentado valerse del binomio tiempo/orden como un motivo literario protagónico

estudio introductorio que realizó Albert R. Braunmuller para su edición de Macbeth (15ss.), de 1999. Por otro parte, a esta edición pertenecen las referencias de Macbeth que aquí extraemos. Recuérdese, por ejemplo, el caso de la censura cristiana a la usura durante el siglo XIII en base a la idea de que aquella práctica suponía un robo a Dios (Le Goff 41ss.). 
dentro de la trama de Macbeth. Sin embargo, es necesario precisar qué es un motivo literario para que la anterior sugerencia tenga asidero.

Según algunas orientaciones y preocupaciones recientes de la filosofía acerca de la conformación del discurso literario, tal como el de la postcritique (Anker and Felski), que rechaza el uso de conceptos como tópico, tema o motivo en la interpretación textual, se han podido observar modificaciones narrativas que implican un nuevo tipo de receptor que, al mismo tiempo, suponen una mirada renovadora sobre algunos enfoques interpretativos que centraban su atención sobre lo que se podría entender como arcaizados conceptos literarios. Este nuevo receptor penetraría en el código literario y sería capaz de encontrarse con hitos básicos que tienen una peculiar tendencia a perdurar, y otros que, por el contrario, se ven sometidos a las contingencias históricas y culturales. Desde esta perspectiva, el nuevo tipo de lector avezado, o crítico literario, podría enfrentarse a la paradoja entre lo fijo y lo accesorio, o entre lo constante y lo cambiante. De hecho, uno de los elementos literarios que manejan esta dualidad es el motivo. Elizabeth Frenzel sostiene que los motivos son más fáciles de reconocer cuando se refieren a unidades de sentido más pequeñas que están incluidas en los temas y que, al rastrearlos en diferentes autores de diferentes países pueden llegar a convertirse en tópicos. Según sus palabras, el motivo sería una "pequeña unidad temática recurrente que se mantiene en la tradición, pero cuyos orígenes son ignotos" ${ }^{\text {. Estas }}$ unidades temáticas, o "unidades de sentido indivisible", al decir de Boris Tomachevski (186-188), pueden ser de dos tipos, dependiendo del carácter funcional que desempeñan dentro del tema: un motivo asociado es aquel que no puede ser excluido sin afectar la causalidad de los eventos, mientras uno libre es aquel que podría ser retirado de la causalidad de los hechos sin modificar directamente el tema. Asimismo, los motivos también pueden ser dinámicos o estáticos, dependiendo de si modifican o no la situación dentro de la cual se da la causalidad de los hechos.

\footnotetext{
Y agrega "El argumento va unido a nombres y acontecimientos fijos y deja sólo ciertos puntos en blanco en el abigarrado curso de la trama, aquellos enigmas o lagunas en materias susceptibles de desarrollo que constantemente atraen a nuevos autores para intentar soluciones, mientras que el motivo con sus personas y datos anónimos señala exclusivamente un planteamiento de la acción con posibilidades de desarrollo muy diversas" (Frenzel VII). Para definiciones diferentes del motivo, véanse las ofrecidas por Trousson, Segré, Brunel, Márquez, Naupert, y López Martínez.
} 
En el caso de Macbeth podemos observar que el tiempo/orden aparece como un motivo dinámico, dado que modifica el desarrollo de los eventos y participa directamente en el desenvolvimiento del argumento de la tragedia. El tiempo, de hecho, está en directa relación con el concepto renacentista de la naturaleza como orden del universo y suma de todas las cosas (Wilson 430). Este motivo está modelado por unas series isotópicas formadas por vocablos o estructuras que remiten o reiteran el motivo mismo: isotopías semánticas que predicen el cambio tales como "shipwrecking storms" (1.2.26) y "direful thunders break"(1.2.26) cuando se da la conversación entre Duncan y un capitán ensangrentado, isotopías de lo impreciso como "the fog and filthy air"(1.1.13) en el momento en que las tres extrañas hermanas terminan sus intervenciones y predicen la inestabilidad de los eventos a seguir, y elementos de la naturaleza tales como "owl", "cricket", que a veces junto a verbos como "scream" o "cry" (2.2.15), mencionados por Lady Macbeth en la conversación que mantuvo con su esposo después de que este haya matado a Duncan, persisten en la idea de crisis del tiempo y/u orden. Otros elementos de la naturaleza, como por ejemplo las estaciones, son utilizadas como ideas de regeneración, de renovación tanto de la naturaleza misma como del tiempo, marcando un nuevo orden de las cosas "So from the spring whence comford seemd to come/ Discomfort swells" (1.2.27-28). Otra forma de concebir este motivo es mediante estructuras como "How goes the world, sir, now?" (2.4.21), donde la presencia del adverbio "now" enfatiza tanto una cierta duración temporal como la misma interrogación; o bien por cláusulas en hiperbatón que insisten en la idea de un nuevo tiempo y de un nuevo orden como en "Shall sun that morrow see" (1.5.59). Esta construcción que se forja a través del nombre "morrow", en tanto forma arcaica de "tomorrow", que en el texto aparece como "to-morrow" o su contrapartida "to-day", en sentido de "hacia el mañana", "hacia el nuevo día, o el nuevo orden", junto al astro "sun", símbolo de lo renovador, y la forma de futuro simple "shall see", evidencian, una vez más, el papel indirecto que aquel motivo tiene en el desarrollo de los eventos. Idea similar a la que aparece en "the time has been $(. .$.$) but now they rise again" (3.4.78-80), donde el pretérito perfecto$ compuesto hace referencia a un pasado con relevancia en el presente o que lo involucra enfatizando así la idea de que existe un pasado que se renueva cual ciclo mediante el cambio. De ahí que pueda decirse que la configuración del motivo tiempo/orden en Macbeth esconde una nota esencial de la tragedia shakesperiana que, de cierta forma, predispone el texto hacia el cambio de orden, perspectiva e interpretación. Sin embargo, estas evidencias no son 
aisladas, sino que se realzan dentro de una totalidad argumental profundamente perturbadora, compuesta por la narración de vertiginosas escenas dentro de las cuales ocurren demasiadas cosas en breves lapsos de tiempo ${ }^{7}$.

Una forma de aproximarse al motivo tiempo/orden de Macbeth podría realizarse por medio de aquella línea que propone restablecer el orden (natural y social) a través de su humanización, al instaurar la necesidad de situarlo dentro de parámetros que les permitan a los humanos participar de sus formas y dinámicas: "this (...) We will perform in measure, time and place" (5.9.38-40). De este modo, la temporalidad que aqueja a Macbeth podría conceptualizarse negativamente, en contraposición a una cotidianeidad "libre de fiestas y banquetes sangrientos", regenerada, henchida de valores sencillos, e inmune a las perversiones casi sobrenaturales que manifiestan los humanos durante sus persecuciones del poder. Tal cosa es lo que trasluce un Lord cuando intenta avizorar un desenlace esperanzador dentro de aquella tragedia atravesada:

we may again

Give to our tables meat, sleep to our nights,

Free from our feasts and banquets bloody knives,

Do faithful homage, and receive free honours,

All which we pine for now.

Pero la contraposición a esta versión más amigable del orden no basta. A medida que el argumento avanza, al menos dos versiones más del tiempo emergen paulatina e intermitentemente: una que guarda relación con la versión lineal, susceptible de cálculo y manipulación, y ligada a la incipiente cultura cortesana, y otra que se caracteriza por la aceleración de esta última, y que hacia el final no puede devenir sino en una destrucción total del tiempo y de todo orden posible.

En lo que se refiere a la temporalidad (u orden) lineal, no pocos han observado que la crisis de Macbeth representa una continuación y un recrudecimiento de la crisis que se había iniciado en Hamlet, poniendo de

\footnotetext{
Tales coordenadas pueden hallarse en Hazlit (12), Bradley (332-333), y Levin. También se ha observado que la composición de la obra presenta varias irregularidades, llevando así a la pregunta de si el texto que conocemos en nuestros días constituye su versión completa. Para los rasgos generales de esta discusión, y una propuesta interesante que repara en las "antinomias temporales" de Macbeth, véase Richardson.
} 
relieve, probablemente, una inquietud del propio Shakespeare acerca del asunto (Piette 1-29). Sobre este asunto, Terry Eagleton (2-3) señaló que los poderes de las brujas, sus danzas de "carnaval", cuerpos grotescos y desafiantes a la vista, y escondrijos fronterizos y sombríos, retan la infertilidad de aquel orden riguroso que había transformado en deporte las luchas por el estatus. Tal deporte cruento y rastrero solo puede incubar esterilidad y muerte dentro del apetito obsesivo de $\mathrm{Macbeth}^{8}$. De manera que la sátira al orden cortesano emergente que se huele en Hamlet se mantiene. Pero a diferencia de Hamlet, Macbeth no lucha por apropiarse genuinamente de su interioridad, sino que se deja devorar por la sed de poder para cargar contra el orden temporal completo. Esto es lo que Donald W. Foster denomina "Macbeth's war on time": una guerra desatada por la búsqueda desenfrenada de la posesión total, incluyendo la vida y la muerte (Foster 324). De esta forma, el malestar brota cuando el deseo infinito que radica en la voluntad de destrucción de Macbeth no puede trascender su mera finitud y colapsa. Su deseo de lo infinito busca eliminar lo finito a través de un "asalto a lo transitorio" que puede describirse como el menoscabo sistemático de los intervalos que hay entre los actos y las reacciones. Por medio de una acción permanente que en muchas ocasiones es ciega, se eliminan las brechas temporales que permiten las reacciones y anticipaciones, y se ingresa en una temporalidad dentro de la cual nada transcurre; todo es absorbido por un tiempo plano para ser congelado y eternizado: este sería, entonces, el rostro de una temporalidad lineal que se radicaliza grotescamente hasta desecarse (333).

Howard Marchiatello, por su parte, entiende que además del problema de la exacerbación del tiempo lineal, Macbeth también retrata la incipiente experiencia de la aceleración social moderna, y se detiene con particular detalle en 1.5, escena en la cual Lady Macbeth se compromete inmediatamente con el destino profético de su esposo a pesar de abrigar intensas reservas hacia él: "Yet I do fear thy nature. / It is too full o'th' milk of human kindness / To catch the nearest way" (1.5.14-16). Allí, Lady Macbeth no demora en fundar

8 Desde la perspectiva de Eagleton, las brujas ofrecen una alternativa al orden cruel y violento de entonces, razón por la cual se habrían visto forzadas a intervenir en el mundo mortal y manipular a Macbeth con el fin de asegurar el surgimiento de una era libre de vilezas, y de la bestial naturaleza humana. Del mismo modo en el que La lucha entre el carnaval y la quaresma (1559) de Pieter Brueghel (el viejo) elimina las distinciones sociales de la tradición, el espacio formal que las obras suelen establecer entre el actor y el espectador se extingue en la extravagante pócima y danza que las hermanas extrañas realizan en 4.1.39-46. 
su apoyo sobre la base del peculiar efecto experiencial/perturbador que trae consigo la velocidad de las acciones:

Great Glamis, worthy Cawdor, Greater than both by the all-hail hereafter, Thy letters have transported me beyond This ignorant present, and I feel now The future in the instant.

Disolver el pasado y el futuro en el instante no hace más que agredir el devenir y lo transitorio, incluyendo así al pensamiento: facultad que a ojos del mismo Macbeth parece quedar muy por detrás de la velocidad con la que actúa su volición. Ilustrativo de esto es el momento en el cual Macbeth asesina a los guardias borrachos que fueron culpados del asesinato de Duncan: ante el reproche de haber perdido una valiosa oportunidad para interrogarlos, Macbeth siguiere que la velocidad de los acontecimientos que acaecieron en su ánimo excedió la posibilidad de su intelección:

Who can be wise, amazed, temp'rate and furious, Loyal and neutral in a moment? No man.

Th'expedition of my violent love

Outran the pauser, reason.

$(2.3 .104-8)$

De ahí que Marchiatello argumente que Macbeth aborda el problema de la desaparición de los cuerpos que genera el incremento de la velocidad de las acciones dentro del tiempo. La completa disolución de los cuerpos de las hermanas extrañas apunta en esta dirección, y además sugiere la idea de que la temporalidad que arrastra al pensamiento es de carácter sobrenatural, no humana, y en consecuencia, incierta y fuera de control (Marchiatello 435). El encuentro que Macbeth y Banquo tienen con las brujas hermanas (1.3) está repleto de incertidumbres: los cuerpos de las brujas respetan las taxonomías humanas, aunque se muestran perturbadoramente estrafalarias; parecen ser mujeres, pero sus barbas insinúan lo contrario; Macbeth las invita a hablar no sin adelantarse a interrogarlas acerca de su capacidad para hacerlo, al mismo tiempo que Banquo las cree imaginarias sin mostrar mucho interés en corroborarlo. Las brujas se mueven en los límites de la apariencia y la realidad, de lo natural y sobrenatural, de lo terrenal y no terrenal, poniendo en tela de juicio el orden que se funda en distinciones, espacios, instantes, y 
clasificaciones (Greenblatt 193). Llegados a este punto, la pregunta que ha librado ríos de tinta refiere justamente al tipo de temporalidad u orden que representan tales hermanas: ¿uno arcaico, tradicional y circular que reacciona ferozmente al nuevo orden lineal del cálculo y viles luchas en busca de poder, o representan la destrucción o suspensión del tiempo que Macbeth trae consigo al acelerar descontroladamente la temporalidad lineal?

\section{LAS EVOCACIONES DEL TIEMPO/ORDEN QUE REPRESENTAN DUNCAN, LADY MACBETH Y MACBETH}

Si bien es ampliamente compartida la lectura que reconoce en Duncan al representante de aquel orden tradicional que se retroalimenta cíclicamente ${ }^{9}$, y en Macbeth a la incipiente linealidad del mundo, no son muchos los que incorporan la aceleración como una tercera temporalidad que deviene en la destrucción de los tiempos/órdenes anteriores. Es verdad que la aceleración no constituye una temporalidad independiente de la lineal, pero es razonable considerarla con cierta autonomía en la medida en que constituye una exacerbación que deviene en autodestrucción.

Pocas dudas existen acerca de que el homicidio de Duncan representa el asesinato figurado del orden tradicional, caracterizado por las formas cíclicas de organización social basadas en el linaje sanguíneo. No obstante, no es tan fácil determinar los órdenes que Lady Macbeth y Macbeth representan, puesto que, como lo hemos sugerido, el tópico de la temporalidad muta de significado e implicaciones a lo largo de la obra, siendo una de las principales razones de esta peculiaridad la de las transformaciones que el matrimonio Macbeth sufre y experimenta. De ahí la necesidad de darnos a la tarea de rastrear sus transformaciones simultáneamente, y precisar los diferentes órdenes temporales que se superponen, oponen y repelen.

\footnotetext{
Según lo observa la edición de Bloomsbury Arden Shakespeare de Macbeth (151, nota 35), no es usual que Duncan utilice nombres particulares o individuales sino más bien términos genéricos dentro de los cuáles caben varios individuos, sin que ello genere confusión. Esto evidencia una estructura social estática que no admite demasiadas movilidades de estatus, a excepción de aquellas que confiere el mismo rey, como puede apreciarse en 1.4.35-36, y al final de la obra con la distribución de earldoms a cargo de Malcolm.
} 
Como puede apreciarse con facilidad, Macbeth no es nada singular en lo que refiere a su comportamiento tradicional. Pelea ferozmente en base a la lealtad que le merece su primo coronado, además de abrigar acostumbradas pretensiones de dignidad y reconocimiento social ${ }^{10}$. Esto queda atestiguado cuando, aún tras escuchar las profecías de las extrañas hermanas y ser alentado por Banquo a recibirlas de buen gusto, Macbeth no puede asegurar la verdad de aquellas ("This supernatural soliciting / Cannot be ill, cannot be good", 1.3.129-30) y resuelve sus cavilaciones en la decisión de dejarse llevar sin participar en el proceso (1.3.43-44).

Luego de esta momentánea resolución de Macbeth entra en juego su esposa. Los agudos análisis que ha despertado aquel célebre pasaje en el cual, tras recibir el encargo por parte de su esposo de preparar un buen recibimiento para el rey, Lady Macbeth le solicita a los espíritus deshacerse de su femineidad para llevar adelante las profecías de las extrañas hermanas (1.5.38-47), ponen de relieve su experiencia lineal del tiempo. La audacia que requiere intervenir en las profecías de las extrañas hermanas es cultivada exclusivamente por Lady Macbeth dentro de la mente de su esposo. Esto es lo que desencadena una vertiginosa transformación caracterológica en él, inicialmente signada por la dolorosa y feroz embestida que le propinan las reservas y preocupaciones ligadas al carácter tradicional que se proponía abandonar (1.7.1-12). La temporalidad lineal trae consigo una nueva forma de organizar el mundo: una en la que los seres humanos pueden proyectarse hacia el futuro sobre la base de lo conseguido en el pasado y objetivado en el presente, y anticiparse así a los escenarios posibles, ya sea para promoverlos, frustrarlos o evitarlos. La temporalidad lineal, en consecuencia, trae consigo una mentalidad que se traduce tanto en una capacidad cognitiva particular, por Reinhart Koselleck (18ss.) denominada prognosis racional, como en una nueva forma de ordenar el mundo natural y social.

10 Si bien no es fácil encontrar pasajes en las obras de Shakespeare que refieran al orden imperante, Eustace Tyllard (8) observa que para los isabelinos era lo suficientemente obvio como para ni siquiera mencionarlo, puesto que lo anteponían a cierto caos que por cierto no creían imperante a sus ojos: "the conception of order is so taken for granted, so much a part of the collective mind of the people, that it is hardly mentioned except in explicitly didactic passages". En convergencia con este punto, Inhae Langis no tiene mayores dificultades para reconstruir el carácter inicial de Macbeth en términos prudenciales, esto es, de acuerdo a la tradicional definición de areté que ofrece Aristóteles. 
Finalmente, Macbeth resuelve "I have no spur / To prick the sides of my intent, but only / Vaulting ambition which o'erleaps itself /And falls on th'other" (1.7.25-28). El pensamiento lineal se esparce por su mente luego del temprano encuentro con su esposa. Pero no solo la linealidad aparece aquí, sino también la necesidad de realizar aquello que Lady Macbeth tan solo pudo visualizar como objetivo a realizar: el futuro en el instante. Terminar con la cadena causal en un mismo acto. De manera que aquella temporalidad que todo lo absorbe no aparece en la obra de forma graduada tras el surgimiento del orden lineal, sino que aparece de improviso, abrupta y conjuntamente con la vorágine de eventos que trascurren en los Actos 1 y 2.

Es tan estremecedora la imagen de esta temporalidad, que en principio el Barón de Cawdor no se cree capaz de éxito. Es preciso que Lady Macbeth insista en su exhortación e interpelación de volverse un sujeto coincidente con el nuevo orden: "¿Art thou afeard / To be the same in thine own act and valour, / As thou art in desire?" (1.7.39-41), a lo que agrega:
When you durst do it, then you were a man.
And to be more than what you were, you would
Be so much more the man. Nor time, nor place
Did then adhere, and yet you would make both,
They have made themselves and that their fitness now
Does unmake you (...)

Esta exhortación no solo echa mano del estereotipo viril disponible en la época, sino que también le exige constituirse como sujeto/sustancia capaz de "reunir tiempo y espacio" para realizar su voluntad, esto es, hacerse uno y el mismo a lo largo del tiempo para poder llevar adelante con éxito las profecías de las brujas hermanas. Lady Macbeth parece tener muy claro que destruir el tiempo a través de la exacerbación de su versión lineal requiere, antes que nada, de la instauración del orden lineal; las posteriores palabras que agrega para reforzar su persuasión no cambian de dirección (1.7.5459), y con ello robustecen la relevancia del rol femenino dentro del Acto segundo. Se necesita mantener la unidad de la identidad, del yo, para llevar adelante un juramento y satisfacer una deuda. Son los rasgos tradicionalmente masculinos que algunos observan en el comportamiento de Lady Macbeth los que guardan relación con la satisfacción de la antesala de la destrucción 
de lo transitorio: la construcción del sujeto ${ }^{11}$. Esto es lo que resuena desde el mismo germinar del plan: "To beguile the time, / Look like the time, bear welcome in your eye, / Your hand, your tongue; look like th'innocent flower, / But be the serpent under't". (1.5.61-64).

En este contexto, la resolución de Macbeth no podría ser más consecuente: "I am settled and bend up / Each corporal agent to this terrible feat. / Away, and mock the time with fairest show, / False face must hide what the false heart doth know" (2.1.79-82); lo cual supone un desdoble interno que parecería ser de su misma autoría. El primer indicio de este desdoblamiento interno se aprecia antes del asesinato de Duncan, cuando al entonces Barón de Cawdor se le enfrenta una peculiar "aparición" que le sugestiona y persuade de llevar adelante la infamia: "Is this a dagger (...) that marshall'st me, and the instrument I was to use" (2.1.33-43). Si bien esta aparición podría no ser más que un producto de su imaginación, es importante realzar su valor protagónico: la daga imaginaria asume una explícita posición actoral, desplazando así al personaje principal para convertirle en objeto o instrumento del orden que las extrañas hermanas parecen querer representar e imponer ${ }^{12}$. Tanto las brujas como la daga ilusoria representan la capacidad que en Macbeth poseen los órdenes y las fuerzas inmateriales para desencadenar consecuencias tangibles y materiales. No obstante, la fuente incierta de tales apariciones (a las que luego se sumará el cadáver de Banquo) solo nos permite sugerir la idea de que no es más que el mismo Macbeth quien se desdobla a lo largo de la obra, vivenciando un desprendimiento entre los órdenes temporal lineal y tradicional dentro de $\mathrm{si}^{13}$. Este desprendimiento se da tanto fuera como dentro de Macbeth, aunque a fin de cuentas, lo más razonable sea identificar su génesis en el "teatro

11 Existe una extensa e intensa discusión en torno a la misoginia que puede hallarse en la obra de Shakespeare. La discusión es amplia y heterogénea en posicionamientos, en virtud de lo cual solo mencionaremos algunos de los enfoques que detectan y analizan la misoginia implicada al papel de las brujas y Lady Macbeth: Montagu, Waith, Asp.

12 Patricia Canning (68-86) sostiene que la fetichización de las imágenes o símbolos es algo recurrente dentro de las producciones dramáticas inglesas renacentistas. Desde su punto de vista, las discusiones en torno a la sujetividad de los objetos fetichizados tienen sus orígenes en las controversias bíblicas de índole exegéticas y teológicas que emergieron a lo largo de la era posreformista.

13 En convergencia con esta lectura, Marina Favila (1-25) sostiene que el rol del pensamiento mágico dentro de Macbeth constituye un elemento clave para la comprensión de la escisión de dos mundos que se influyen recíprocamente, sin lograr sobreponerse definitivamente al espacio que les separa. 
mental" del escocés ${ }^{14}$. De ahí que, luego de la muerte de Duncan, Macbeth afirme enigmáticamente que "To know my deed, "twere best not know my self. / Wake Duncan with thy knocking: I would thou couldst" (2.2. 76-77).

Es la indeterminada contextualidad de la elocución de estas líneas el origen de gran parte de su enigma, pues, no se sabe si es una afirmación retórica, o si por el contrario abriga alguna respuesta significativa para su esposa. No obstante, mucho del sentido de estas líneas descansa en el desdoblamiento que Macbeth se esfuerza por lograr, y no tanto por padecer. El recurso imaginario del que se vale la aparición de la daga es solicitado aquí por el mismo Macbeth para ocultarse a sí mismo algo que de saberlo, o bien lo detestaría, o bien lo destruiría anímicamente. El Macbeth conocido y querido en su época se refleja explícitamente en la segunda línea: un hombre noble que desea ver a Duncan levantarse tras el golpe de nudillos en la puerta; más su nueva impronta lineal, aquella que su esposa le ha exhortado a asumir, le vuelve un completo desconocido. De ahí la necesidad de borrar todo lo que hasta entonces sabía de sí, y evitar con ello comprender su acto como uno tan vil que no tiene precedentes ${ }^{15}$.

De aquí en más, quien fue maldecido por las brujas asume una nueva postura frente al orden que planea destruir. Se autoimpone como un sujeto capaz de calcular y aventajar al resto de sus semejantes por medio de la exacerbación del cálculo y la manipulación, no sin sentir los múltiples y agónicos lamentos

$14 \quad$ Según Richard S. Ide (338-361), uno de los asuntos más difíciles de abordar a la hora de analizar Macbeth es el de cómo se concilian hacia el final de la obra dos perspectivas que hacia el principio se presentan desconectadas: el escenario de la mente que se rige por lo ambiguo, extraño e incómodo, y el escenario del mundo. De acuerdo con su análisis, ambas perspectivas se reconcilian paulatinamente hacia el final de la batalla del Acto 5, luego de crear las coordenadas básicas suficientes como para que el espectador pueda asumir el punto de vista de Macbeth, algo que hasta entonces parece imposible. Por su lado, Andrew Bradley (97-130) ya había insistido en la idea (hoy ampliamente compartida) de que es el mismo Macbeth quien crea y da vida, fetichizadamente, a las imágenes y apariciones que se le enfrentan, puesto que una lectura opuesta iría en contra de la totalidad de la práctica teatral de Shakespeare.

15 Nótese que hacia el final de la primera línea en cuestión se escribe "my self", lo que podría responder a la costumbre de la época de separar palabras, en este caso "myself" (como ocurre con "to day" -5.5.19), o bien podría significar literalmente "mi yo", o identidad. Si es este último el caso, estaríamos frente al tópico de la interioridad que es percibida desde el punto de vista de la propiedad (como sucede en Hamlet, 1.2.85-86: "But I have that within which passeth show- / These but the trappings and the suits of woe"), lo que reforzaría la hipótesis del autoengaño que Macbeth podría estar elaborando para llevar adelante la empresa originalmente ideada por su esposa. 
que la era desgarrada le hace llegar: en el mismo instante en que Macbeth le arrebata la vida a su primo, los demás individuos durmientes sueñan, ríen, lloran, maldicen y gritan desesperados, mientras los búhos chillan inquietantemente toda la noche (2.2). Los signos del dolor del tiempo tradicional, cíclico y natural que desaparece vuelven a ser brutalmente ilustrados en 2.4, durante el diálogo que Ross mantiene con el anciano: un halcón es cazado por una lechuza; el sol, la luz y el día ceden "vergonzosamente" ante el imperio de la noche; y finalmente, dos caballos de Duncan escapan, desafían a los hombres, y se devoran entre sí. El anciano no puede menos que ver burlado todo su saber tradicional ("former knowings", 2.4.1-3) y concluir que todo aquello "Tis unnatural" (2.4.10).

La personificación del tiempo tradicional, onírico, y natural en Duncan, se contrapone a la artificialidad del nuevo orden que Macbeth planea implantar; un orden que si bien es lineal, abandona pronto su promesa de libertad para ceder ante la sed de poder y el miedo a la muerte. De manera que los componentes positivos que trae consigo el orden lineal no logran imponerse en Macbeth, como sí parecen hacerlo en Hamlet: mientras Hamlet sucumbe al orden temporal impuesto por Claudius para convertirse en sujeto y poder saldar su deuda con el orden descoyuntado, Macbeth impone el nuevo orden lineal sin querer con ello perpetuarlo, puesto que tal cosa le impediría mantener la corona. El nuevo rey de Escocia se hace del tiempo lineal para imponerlo e inmediatamente destruirlo, asegurando así el quebranto de las sucesiones temporales, y la eternización de su nueva posición social. Esta es la razón por la cual los escollos y desenlaces que le siguen al Acto segundo describen poco a poco cómo el nuevo rey intenta destruir toda temporalidad, sea esta tradicional o lineal, a través del vértigo, la aceleración, y el "asalto a lo transitorio"16.

16 Las hipótesis de la demencia, ambición, y obsesión podrían no hacer justicia al thelos del apetito devorador de Macbeth. Atendiendo al hecho de que su matrimonio no había podido obtener descendencia, cabe concebir la posibilidad de que subterráneamente exista un deseo de permanecer y transmitir el legado familiar heredado desde tiempos remotos. Hallamos así una posible justificación del plan de Macbeth: eternizar el presente para que su legado no desaparezca del mundo, lo cual converge con nuestra reconstrucción del desdoblamiento interno y autoengaño que el protagonista parece llevar adelante a partir del Acto segundo. Múltiples estudios realizados en torno a los significados asociados a la frustración corporal, sexual y reproductiva del matrimonio Macbeth dentro del contexto isabelino apuntan elementos similares. Para una reconstrucción de este último asunto, véase Barmazel. 


\section{ACELERACIÓN, DESTRUCCIÓN MOMENTÁNEA DEL TIEMPO/ORDEN Y CONSECUENCIAS}

A pesar de que el accionar de Macbeth es vertiginoso e impredecible, el orden/ tiempo lineal no se deja destruir con facilidad. Indicio propio de ello es el sentido de culpa que aqueja a Macbeth tras ser informado del asesinato de Banquo (3.4.75-82). Dentro del orden tradicional que se genera y regenera dentro de un tiempo circular o cíclico no existe la culpa o remordimiento, puesto que el orden se retroalimenta y elimina a todo aquel que desee modificar su curso inmanente. A cada individuo que ose aventajar el orden preestablecido por el ciclo le aguarda un castigo que no siempre se traduce en la desposesión de su vida, sino en la desposesión de su estatus/identidad, arrojándole a vagar sin fin y consuelo por una suerte de purgatorio social. De manera que Macbeth se avergüenza de su acto para con Banquo porque pudo desarrollar una mentalidad moderna capaz de recorrer el tiempo linealmente hacia adelante y hacia atrás, permitiéndole así generar una memoria de sus actos y, finalmente, responsabilidad y culpa por ellos ${ }^{17}$. De ahí que Macbeth también se proponga destruir el nuevo orden que le sirvió para alcanzar su posición real. La linealidad le asalta en la medida en que le obliga a crear una memoria que le permita ser uno y el mismo a lo largo del tiempo. De este modo, el pasado y el futuro le asfixian simultánea y furiosamente: el primero le golpea con resentimientos, culpas y deudas, mientras el segundo cultiva en su estómago la angustia de la incertidumbre de su nueva posición, deviniendo en miedo y obsesión. Pero la solución del escocés ya había madurado en la mente de su esposa: lograr que el futuro se disuelva en el instante. Acelerar el tiempo hasta que este brinque de sus goznes y paralice todo aquello que dentro de él se mueve.

Macbeth expresa en repetidas ocasiones el objeto de su sed: "Strange things I have in head that will to hand, / Which must be acted ere they may be scanned" (3.4.139-140). De hecho, este pasaje es crucial para observar cómo Macbeth emprende su segunda transformación, alejándose así de su esposa,

17 El tiempo lineal constituye para Nietzsche (621ss.) la conditio sine qua non de la construcción de la sustancia humana que se mantiene continua a lo largo del tiempo para poder responder por sus acciones pasadas. Desde su perspectiva, el sujeto de "voluntad larga" no es más que la construcción social de un mecanismo de supervivencia que estuvo a cargo de los débiles, y que se materializa por medio de castigos corporales y transacciones económicas. El sujeto moderno, a fin de cuentas, no es más que un "animal al que le [es] lícito prometer". 
quien de aquí en adelante adopta una postura de cuidado y consternación ${ }^{18}$. El simple hecho de que Macbeth no pueda dormir pone de relieve la naturaleza del nuevo orden temporal que comienza a imponerse: uno que no tiene naturaleza, ni "temporadas" (3.4.141), ni transcurre, y que, en consecuencia, deja las cosas como están. La decisión de asaltar vilmente el castillo de Macduff y asesinar a todos los que allí vivían reafirma este punto, y hace evidente su estrategia de asaltar lo transitorio para eliminar la posibilidad de que sus enemigos puedan reaccionar a sus acciones (4.1.143-148).

El tercer orden/tiempo que disuelve las diferencias no parece ser muy distinto de aquel que representan las extrañas hermanas. Desde el inicio aquellas proponen eliminar las distinciones en una univocidad que todo lo engulla, que licúa las diferencias entre las batallas perdidas y ganadas (1.1.4), y dentro de lo cual "Fair is foul, and foul is fair" (1.1.12). La enfermedad de la nación a la cual se refieren Malcom y Macduff podría apuntar en la dirección de este nuevo orden que no reconoce diferencias ni distinciones, que todo instante niega, y que todo cambio prohíbe ${ }^{19}$. Un orden que ofrece ilusorias recompensas al más veloz de los actores, puesto que a pesar de su talento, tampoco podrá escapar de las cadenas que sus propias consecuencias echarán sobre su cuello.

Se sabe que el más veloz de Macbeth no es Macbeth sino Macduff, alguien que a pesar de participar del orden tradicional nació antes de tiempo. Pero este asunto no deja de ser polémico. Ante la exclamación "The time is free" (5.9.22) de Macduff, uno no puede dejar de preguntarse acerca de qué tiempo,

18 Stephanie Chamberlain (72-91) es una de las pocas críticas literarias que se resiste a interpretar el rol de Lady Macbeth en términos masculinos. Desde su perspectiva, la provisoria reina de Escocia desempeña una "maternidad condicionada" en virtud de que, a pesar de haber planeado vehementemente el asesinato de Duncan, no demora mucho en recuperar su actitud de cuidado y atención. Este cambio de perspectiva de Lady Macbeth sugiere, en consecuencia, que el papel desempeñado a lo largo del Acto 2 no debe ser considerado como un rasgo duradero y característico de su personalidad, sino como una transformación provisoria y no constitutiva. Un tratamiento diferente, aunque convergente, de esta ambigüedad de Lady Macbeth puede hallarse en Carroll (344-368).

19 A partir de la idea de una temporalidad que congela el ser en estados se han podido trazar, recientemente, algunas coordenadas que orientan el estudio teórico y terapéutico de la depresión y melancolía. Christian J. Churchill (161-174), por ejemplo, ha echado mano de la peculiar temporalidad de Macbeth para señalar que la experiencia personal del tiempo de los depresivos y melancólicos constituye un elemento fundamental, si no prioritario, a ser tomado en cuenta para la elaboración de una terapia exitosa. 
era u orden es el que ha sido liberado. En primera instancia parecería que el orden tradicional se ha restablecido a través de la continuación sanguínea que representa el futuro reinado de Malcom, más, la sangre no real de Banquo continua perdida en algún lugar de Escocia. Lo importante de este asunto consiste en que, en caso de que las profecías de las extrañas hermanas fueran verdad, no parece existir medio por el cual los herederos de Banquo puedan alcanzar la corona según las reglas estructurales del orden tradicional. Este cabo sin atar podría sugerir la idea de que el germen del nuevo orden temporal que representa Macbeth es capaz de brotar eventualmente en la sangre de los herederos de Banquo, envolviendo así a toda la obra bajo el manto de la profecía.

Así las cosas, Macbeth podría estar avizorando premonitoriamente lo que habría de suceder en un futuro no muy lejano al siglo XVII. Así parece sugerirlo el célebre soliloquio que pronuncia Macbeth tras ser informado de la muerte de su esposa:

She should have died hereafter;

There would have been a time for such a word.

To-morrow, and to-morrow, and to-morrow,

Creeps in his petty pace from day to day

To the last syllable of recorded time,

And all our yesterdays have lighted fools

The way to dusty death. Out, out, brief candle!

Life's but a walking shadow, a poor player

That struts and frets his hour upon the stage

And then is heard no more. It is a tale

Told by an idiot, full of sound and fury,

Signifying nothing.

Los quiebres léxicos que podemos detectar en "To-morrow, and to-morrow, and to-morrow" y "day to day" construyen una rítmica que gira en torno a un vacío, probablemente creado por una escisión; lo que podría obedecer al estilo de escritura de entonces, o a una rebuscada forma de referirse al tiempo descoyuntado. No obstante, el bucle temporal que tal ritmo sugiere parece ser algo imposible de no observar: al leer estas líneas es irresistible sentir la necesidad de utilizar alguna de nuestras manos para seguir el ritmo poético y dibujar un bucle imaginario que, a pesar de volver sobre sí, no deja de avanzar "hasta la última sílaba del tiempo recordado". 
Pero el soliloquio no atiende las promesas del bucle temporal sino a su destrucción: el absurdo que se desencadena cuando una de las temporalidades que componen el bucle se asume y radicaliza grotescamente. En cierto modo, la propuesta de destruir toda temporalidad constituye un intento fallido de eludir el dilema que plantean las promesas proféticas: "This supernatural soliciting / Cannot be ill, cannot be good" (1.3.129-130). Este dilema no es resuelto a lo largo de la obra, así como tampoco afrontado. ¿Acaso Shakespeare habrá querido mofarse de la laxitud con la que echamos mano de los juicios morales, o habrá tenido la intención de mostrarnos la imposibilidad de no afrontar y asumir alguna postura con respecto a ello? Probablemente, Macbeth se esfuerza por expresar el profundo problema que descansa en la tarea de tomar decisiones correctas, ilustrando, a su paso, la futilidad de intentar sortear o destruir el asunto ${ }^{20}$. Parece obvia la idea de que los intelectuales deben mirar y enfrentar directamente la complejidad de los problemas, pero nadie deja de tomar decisiones aun a sabiendas de que los contextos que nos envuelven se estructuran en base a la explotación, injusticia y crueldad. En todo caso, solo algunos pocos se sumergen en la indecisión. De ahí que Macbeth no deje de intentarlo hasta el final ("Yet I will try the last", 5.8.32), a pesar de ser consciente de la treta profética de las brujas, lo cual nos interpela a preguntar cómo podemos afrontar y/o resolver las crisis temporales (y de órdenes) que acarrea la aceleración social de hoy ${ }^{21}$.

Dejando de lado el atrapante asunto de si Macbeth podría ser considerado o no una profecía de nuestro tiempo/orden, cabe al menos concluir que la destrucción del tiempo constituye en esta obra tanto un motivo literario como un síntoma de las transformaciones sociales, culturales y subjetivas que supo atravesar la temprana modernidad. De alguna manera, el motivo literario coagula inquietudes epocales ligadas a vicisitudes sociales que perturbaron tanto las formas de organización social como las maneras de intelectualizar y habitar el tiempo de entonces: la secularización que comienzan a sufrir

$20 \quad$ A lo largo de los últimos tres siglos y medio no ha mermado la discusión acerca de si Macbeth presenta y/o aborda asuntos morales. Al día de hoy, existen múltiples intentos de psicologizar la obra, de reducir a Macbeth y su esposa a la demencia, de subyugar su mensaje al contexto de los siglos XVI-XVII, etc., utilizando como principal campo de discusión el de la interpretación, traducción, y adaptación teatral de la obra. Véase un recorrido ilustrativo de esta polémica en Moschovakis.

21 Véase una consideración crítica de la aceleración social en Rosa, y una optimista en Srnicek y Williams. 
las instituciones europeas a fines del medioevo, el contacto con el Nuevo Mundo y el nacimiento de las ciencias de la estadística y probabilidad que muy pronto se afilian con el naciente mercado del aseguramiento de naves marítimas, intensifican la trabazón que mantienen el tiempo cronológico y las formas de ordenar lo social hasta volverla un rasgo distintivo de la coyuntura tempranomoderna (Koselleck 26-42). De ahí que Shakespeare parezca haber sido prodigiosamente consciente de su condición histórica, y haya podido expresar parte de sus impresiones a través de las voces de Hamlet, Macbeth, y Warwick en Henry IV:

There is a history in all men's lives, Figuring the natures of the times deceased; The which observed, a man may prophesy, With a near aim, of the main chance of things As yet not come to life, which in their seeds And weak beginnings lie intreasured.

(II.3.1.80-85) 22

Mientras Hamlet parece observar y acusar las transformaciones temporales y sociales de su época, y Warwick interpreta las posibilidades humanas que ambas ofrecen, Macbeth parece encargarse de materializar, casi cual profecía, el desenlace que todo aquello sugería prometer. Sin embargo, en virtud de que las formas de intelectualizar y habitar el tiempo determinan las formas posibles que puede asumir la vida social (tradicional dentro de las estructuras temporales cíclicas, y modernas dentro de las estructuras temporales lineales), la destrucción del tiempo significa una crisis de las formas de organización social en general que pone sobre el tapete el asunto de qué tipo de vida conjunta vale la pena llevar adelante. De manera que el tema literario escogido por Shakespeare podría no solo remitir a las dificultades que la aceleración de las actividades trae consigo durante la persecución del poder, sino también, y al mismo tiempo, a la oportunidad que todo aquello produce para crear formas de vida más amigables, pues, por imposible que llegue a parecer en algunos momentos determinados, ningún orden social puede sostenerse por siempre ${ }^{23}$.

22 Extraída de la edición de John Dover Wilson de 2009.

23 Las objeciones, sugerencias y correcciones realizadas por los/as dictaminadores/ as de Revista Chilena de Literatura han sido de un incalculable valor a la hora de optimizar las argumentaciones aquí presentadas. Sirva esta nota para expresar nuestra profunda gratitud hacia ellos/as. 


\section{BIBLIOGRAFÍA}

Anker, Elizabeth S., and Rita Felski. Eds. Critique and Postcritique. Durham: Duke University Press, 2017.

Asp, Carolyn. "'Be bloody, bold, and resolute': Tragic Action and Sexual Stereotiping in Macbeth". Studies in Philology 78.2 (1981): 153-169.

Ayers, Philip J. "Degrees of Hersey: Justified Revenge and Elizabethan Narratives". Studies in Philology 69.4 (1972): 461-474.

Barmazel, Julie. "The servant defect'. Macbeth, impotence, and the body politic". Macbeth. New Critical Essays. Ed. Nick Moschovakis. London/New York: Routledge, 2008. 118-131.

Bradley, Andrew C. "Shakespeare". Shakespeare. Macbeth. Ed. J. Wain. London: Macmillan, 1968. 97-130.

Shakespearean Tragedy: Lectures on "Hamlet," "Othello," "King Lear," "Macbeth". London: Macmillan \& Co., 1904.

Brunel, Pierre. "Thématologie et littérature comparée". Exemplaria: Revista de literatura comparada 1 (1997): 3-12.

Canning, Patricia. "Fatal Visions': The Image as Actor in Early Modern Tragedy”. Early Modern Drama and the Bible: Contexts and Readings, 1570-1625. Ed. Adrian Streete. Houndsmills: Palgrave Macmillan, 2012. 68-86.

Carroll, William C. Ed. Macbeth: Texts and Contexts. Boston: Bedford/St. Martin's, 1999.

Chamberlain, Stephanie. "Fantasizing Infanticide: Lady Macbeth and the Murdering Mother in Early Modern England”. College Literature 32.3 (2005): 72-91.

Churchill, Christian J. “'Is That All There Is?': Time, Guilt, and Melancholia. Sleep No More and Macbeth", International Journal of Applied Psychoanalytic Studies 12.2 (2015): 161-174.

Eagleton, Terry. William Shakespeare. Oxford: Basil Blackwell, 1986.

Favila, Marina. "'Mortal Thoughts' and Magical Thinking in Macbeth”. Modern Philology 99/1 (2001): 1-25.

Foster, Donald W. “Macbeth's War on Time”. English Literary Renaissance 16 (1986): 319-342.

Frenzel, Elizabeth. Diccionario de motivos de la literatura universal. Madrid: Gredos, 1980.

Greenblatt, Stephen. Hamlet in Purgatory. Princeton: Princeton University Press, 2001.

Hazlit, William. Characters of Shakespeare's Plays. London: Oxford University Press, 1917.

Ide, Richard S. "The Theatre of the Mind: An Essay on Macbeth". ELH: A Journal of English Literary History 42.3 (1975): 338-361.

Koselleck, Reinhart. Future Past. On the Semantics of Historical Time. New York: Columbia University Press, 2004.

Le Goff, Jacques. La bolsa y la vida. Economía y religión en la Edad Media. Barcelona: Gedisa, 1987.

Levin, Harry. "Two Scenes from Macbeth". Shakespeare's Craft: Eight Lectures. Ed. Philip H. Highfill Jr. Carbondale: Southern Illinois University Press, 1982. 48-68.

López Martínez, María Isabel. El tópico literario. Madrid: Arco Libros, 2007.

Marchiatello, Howard. "Speed and the Problem of Real Time in Macbeth". Shakespeare Quarterly 64.4 (2013): 425-448. 
Márquez, Miguel Ángel. “Tema, motivo y tópico. Una propuesta terminológica”. Exemplaria: Revista de literatura comparada 6 (2002): 251-256.

Montagu, Elizabeth. "The Genius of Shakespeare". Macbeth: Authoritative Text, Sources and Contexts, Criticism. Ed. Robert S. Miola. New York: Norton Critical Editions, 2004. 211-215.

Moschovakis, Nick. "Dualistic Macbeth? Problematic Macbeth?". Macbeth. New Critical Essays. Ed. Nick Moschovakis. London/ New York: Routledge, 2008. 1-72.

Naupert Naumann, Cristina. Tematología y comparatismo literario. Madrid: Arco Libros, 2003.

Nietzsche, Friedrich W. La genealogía de la moral. Un escrito polémico. Madrid: Gredos, 2010.

Piette, Adam. "Performance, Subjectivity and Slander in Hamlet and Much Ado About Nothing". Early Modern Literary Studies 7.2 (2001): 1-29.

Richardson, Brian. "'Horse Dreadful and Things Strange': Inversions of Chronology and Causality in Macbeth". Philological Quaterly 68 (1989): 283-293.

Rosa, Hartmut. Social Acceleration: A New Theory of Modernity. New York: Columbia UP, 2013.

Schmidt, Alexander. Shakespeare's Lexicon and Quotation Dictionary. 2 vols. New York: Dover Publications, Inc., 1971.

Segré, Cesar. Principios de análisis del texto literario. Barcelona: Crítica, 1985.

Seymour, E.H. Remarks critical, conjectural, and explanatory, upon the plays of Shakespeare. Resulting from the collocation of the early copies with that of Johnson and Steevens. Ed. Isaac Reed together with some valuable extracts from the mss. of the Late Right Honourable John, Lord Chedworth. Dedicated to Richard Brinsley Sheridan. Vol. II. London: J. Wright for Lackington, Allen \& Co., 1805.

Shakespeare, William. Macbeth. Eds. Sandra Clark and Pamela Mason. London: Bloomsbury Arden Shakespeare, 2015.

The Second Part of the History of Henry IV. En The Cambridge Dover Wilson Shakespeare: Vol. 9. Ed. John Dover Wilson. New York: Cambridge University Press, 2009.

Hamlet. Prince of Denmark. Ed. Philip Edwards. California: Cambridge University Press, 2003.

Macbeth. Ed. A. R. Braunmuller. Estudio introductorio de A. R. Braunmuller. Cambridge: Cambridge University Press, 1999.

Srnicek, Nick and Alex Williams. Inventing the Future. Postcapitalism and a World Without Work. London/New York: Verso, 2015.

Tillyard, Eustace M. W. The Elizabethan World Picture. London: Penguin, 1990.

Tomachevski, Boris. Teoría de la literatura. Madrid: Akal, 1982.

Trousson, Raymond. Un problème de littérature comparée. Les études des temes. Paris: Lettres Modernes, 1965.

Unhae, Langis. "Shakespeare and Prudential Psychology: Ambition and Akrasia in Macbeth". Shakespeare Studies 40 (2012): 44-52.

Waith, Eugene M. "Manhood and Valor in Two Shakespearean Tragedies". ELH: A Journal of English Literary History 17.4 (1950): 265-268.

Wilson, Harold S. "Meanings of 'Nature' in Renaissance Literary Theory". Journal of the History of Ideas 2.4 (1941): 430-448. 